\title{
ESTÁGIO E ENSINO MÉDIO: COMPLEXIDADES DE UMA RELAÇÃO
}

Rosa Maria Bortolotti de Camargo

rosabortolottti@gmail.com Mestranda do PPGE da Universidade Federal de Santa Maria

Profa. Dra. Rosane Carneiro Sarturi rcsarturi@gmail.com Docente do Programa de Pós-graduação em Políticas Públicas e Gestão Educacional da Universidade Federal de Santa Maria 
RESUMO: Este estudo insere-se no campo das políticas públicas educacionais que orientam as práticas de estágios remunerados para jovens estudantes da etapa do ensino médio (EM). O objetivo é identificar algumas das complexidades produzidas pelo contexto político e prático do exercício de estágios remunerados que realizam alguns estudantes do ensino médio como auxiliares pedagógicos em Escolas Municipais de Educação Infantil (EMEI). A pesquisa é qualitativa do tipo estudo de caso e a coleta de dados se deu por meio de entrevistas semiestruturadas e da observação participante. Utilizaram-se como referencial teórico os estudos dos autores sobre o tempo da juventude e da infância: Melucci (1996), Pais (2006), Kuhlmann (2000) entre outros. Entende-se que a falta de força de trabalho especializada, na cidade de Santa Maria, para atuar na etapa da Educação Infantil (EI) tem propiciado o contrato de jovens da etapa do EM para serem os auxiliares pedagógicos. Porém, a relação entre estágio, juventude e EI produz questões que devem ser refletidas com criticidade sobre o tipo de formação que ser proporcionar, e que vem sendo proporcionada, tanto para os jovens atuarem no mercado do trabalho, uma vez que eles exercem funções que não coincidem com os seus estudos e vontades pessoais, quanto para as crianças pequenas, que acabam sendo atendidas por jovens que não são formados para trabalhar e desenvolver atividades que estimulem o desenvolvimento infantil.

PALAVRAS-CHAVE: ensino médio e juventude, educação infantil e infância, relação estágio e renda.

\section{STAGE AND HIGH SCHOOL: COMPLEXITIES OF A RELATIONSHIP}

ABSTRACT: This study is based on the public educational policies that guide the practices of paid internships for young high school students. This paper aims to identify some of the complexities produced by the political and practical context of the paid internships that some high school students perform as pedagogical assistant in a municipal school of elementary education. This is a qualitative research based on a case study and the data collection was made through semi-structured interviews and participant observation. For the theoretical reference, were used authors who study youth and childhood period: Melucci (1996), Pais (2006), Kuhlmann (2000) among others. It is understood that the lack of skilled workforce, in the city of Santa Maria, to work in elementary has provided the hiring of this high school students to be pedagogic assistants. However, the relationship between internship, youth and elementary education creates contradictions when it comes to orienting this youth to the job market; since they are performing tasks that do not coincide with their studies and personal desires, as well as for young children and their childhood, since they end up being attended by professionals who are not qualified to perform this assignment.

KEYWORDS: high school and youth, elementary education and childhood, internship and income. 


\section{Introdução}

Este estudo contou com apoio do Programa Observatório da Educação (OBEDUC), da Coordenação de Aperfeiçoamento de Pessoal de Nível Superior (CAPES) Brasil, na Universidade Federal de Santa Maria (UFSM). Tem como objetivo identificar algumas das complexidades produzidas pelo contexto político e prático do exercício de estágios remunerados que realizam alguns estudantes do ensino médio como auxiliares pedagógicos em Escolas Municipais de Educação Infantil (EMEI).

No senso comum que circunda as políticas públicas para as etapas da educação infantil (EI) e do ensino médio (EM), se nos detivermos nas faixas etárias atendidas, elas parecem estar muito distantes, enquanto a primeira atende crianças de zero a seis anos, a segunda trabalha com a última etapa da educação básica, que tem como público alvo os jovens. Os fatores legais que convergem essas etapas e gerações seria o fato de que são legalmente garantidas e institucionalizadas pela organização política educacional brasileira, a qual prevê a educação básica obrigatória e gratuita dos quatro aos dezessete anos de idade. No que refere ao direito e proteção, todos estão igualmente amparados pela Lei $\mathrm{n}^{\text {o }}$ 8.069, de 13 de julho de 1990 (BRASIL, 1990), que estabelece o Estatuto da Criança e do Adolescente (ECA).

Se esse distanciamento poderia desenhar uma contradição entre essas duas etapas, no contexto prático da cidade de Santa Maria percebe-se que ambas estão longe de não convergirem para além dos quesitos legais, pois, 79\% dos estagiários contratados para trabalham como auxiliares pedagógicos nas EMEI da cidade são jovens matriculados no EM. Os dados levantados no Setor de Estágios da Prefeitura Municipal ${ }^{1}$ revelam que da soma de 188 contratos de estágios, 147 são de estudantes da última etapa da educação básica (EB), sendo os 41 restantes, alunos do ensino superior (ES), das universidades púbicas e privadas da cidade e dos cursos como: Pedagogia, Psicologia, Educação Física, Matemática, da Pós-Graduação, entre outros.

\footnotetext{
${ }^{1}$ Tais dados foram obtidos a partir da Lei $\mathrm{n}^{\mathrm{o}} 12.527$, de 18 de novembro de 2011 , que regula o acesso à informação de dados das instituições em todas suas instâncias (BRASIL, 2011). Foi requerido, ao Setor de Estágios, da Prefeitura Municipal de Santa Maria, o número de estagiários lotados na Secretaria de Educação que realizam estágios nas EMEI, constando o nível de escolaridade dos mesmos. Os dados obtidos são referentes ao último relatório gerado em maio de 2015.
} 
Conforme os dados do Instituto Nacional de Estudos e Pesquisas Educacionais “Anísio Teixeira” (INEP), até o ano de $2014^{2}$, o município matinha um total de $8.970^{3}$ matrículas no EM. Nesse sentido, se tomarmos como referência o número de contratos do EM mencionados, com a totalidade de jovens matriculados no EM, veremos que os estudantes que realizam estágios remunerados representavam 1,62\% das matrículas no EM. Considerando que esse valor ainda é significativamente baixo, no que refere às matrículas dessa etapa, o mesmo converte-se em um dado significativo se comparado ao número de estudantes dos Cursos de Pedagogia que realizam a mesma função. Segundo o relatório disponibilizado, o número de estudantes de Pedagogia que realizam estágios é de 18 estudantes; ou seja 9, 57\% dos estagiários das EMEI:

Tabela 1. Relação formação e estagiário.

\begin{tabular}{|c|c|c|}
\hline Formação & $\mathbf{N}^{\circ}$ de estudantes & Porcentagem \\
\hline Ensino Médio & 147 & $79 \%$ \\
\hline Pedagogia & 18 & $9 \%$ \\
\hline $\begin{array}{c}\text { Outros Cursos Superiores } \\
\text { (Educação Física, Pós- }\end{array}$ & 23 & $12 \%$ \\
Graduação, Matemática) & & \\
\hline
\end{tabular}

Fonte: Secretaria da Educação (2015)

A Lei ${ }^{\circ} 11.788$, de 25 de setembro de 2008 (BRASIL, 2008) é responsável pela regulamentação dos estágios nas EMEI administrados a partir de um convênio entre a Prefeitura Municipal de Santa Maria, especificamente, a Secretaria Municipal de Educação (SMED), o Centro de Integração Empresa Escola (CIEE) e a (s) EMEI. Tal legislação considera o estágio remunerado como:

Art. $1^{\mathrm{o}}$ : Estágio é um ato remunerado que visa à preparação para o trabalho produtivo de educandos que estejam frequentando o ensino regular em instituições de educação superior, de educação profissional, de ensino médio, da educação especial e dos anos finais do ensino fundamental, na modalidade profissional da educação de jovens e adultos (BRASIL, 2008).

O convênio estabelece que o pagamento dos auxiliares se dê pela municipalidade e que o CIEE tome para si a responsabilidade de fazer um cadastro de estudantes que queiram realizar estágios remunerados nas EMEI. Por meio desse cadastro, o jovem passa a fazer parte de um banco de dados, quando surge a necessidade de contratação de um

\footnotetext{
${ }^{2}$ No momento da realização da pesquisa, os dados do INEP de 2015 ainda não tinham sido divulgados.

${ }^{3}$ Aqui, foram somadas todas as matrículas do ensino médio, ou seja, as matrículas do ensino médio regular, ensino médio educação profissional (Nível Técnico), educação de jovens e adultos (Presencial) e educação de jovens e adultos (semipresencial).
} 
novo auxiliar em alguma EMEI da cidade, o CIEE realiza o chamamento do estudante até seu estabelecimento para a realização de um processo seletivo. Nesse processo seletivo, além da entrevista há uma avaliação de conhecimentos pedagógicos e do cuidado com a criança que o candidato deve fazer, contudo, não obtivemos autorização para divulgá-las. Em alguns casos, há jovens que são selecionados pela escola antes de realizarem o cadastro CIEE. Isso ocorreu com uma das jovens de nossa pesquisa. A jovem era da comunidade em que a EMEI estava localizada e tinha uma irmã na escola. Ela vinha demonstrando interesse pelo cuidado de crianças, então a diretora convidou-a para realizar um estágio na escola na função de auxiliar. Assim, o processo de seleção se deu de forma inversa, a jovem já foi para o CIEE, indicada para estagiar em uma escola prédeterminada ${ }^{4}$.

Se essa prática parece estar em conformidade com a legislação, ao mesmo tempo ela produz algumas questões no interior dos estudos sobre estágio e juventude, bem como nos estudos sobre a infância e EI. Seria esse estágio remunerado um diálogo inicial do jovem com o mundo do trabalho? A função de estagiário garantiria a qualidade do atendimento das crianças na (s) EMEI? Existe uma relação entre os estágios e a vivência da juventude?

Valendo-se da pertinência e amplitude de tais questionamentos, este estudo foi desenvolvido com a expectativa de poder abrir um espaço de discussão em torno do tema sobre políticas públicas educacionais que orientam as práticas de estágios remunerados, considerando os estágios realizados por alguns jovens nas EMEI da cidade de Santa Maria. Foi uma oportunidade de levantarmos aspectos importantes sobre a relação do estágio com a vivência da juventude bem como o atendimento das crianças pequenas na contemporaneidade.

\footnotetext{
${ }^{4}$ A descrição deste procedimento seletivo foi realizada a partir das observações participantes, nos momentos de conversa informais com os sujeitos de pesquisa, os quais foram nos descrevendo o procedimento do processo seletivo. Assim, este parágrafo é o resultado sintético de um conjunto de falas escutadas durante o processo da pesquisa.
} 


\section{Metodologia}

Essa pesquisa é fruto de um Trabalho de Conclusão de Curso $^{5}$ (TCC), realizando no ano de 2015, no curso de Pedagogia Noturno, da UFSM. Foi realizada através de um estudo de caso qualitativo em que os dados foram coletados através da observação participante e entrevistas semiestruturadas. Sendo assim, a pesquisa desenvolveu-se buscando interpretar as complexidades no seio interior da relação estágio e juventude nas EMEI.

Essa relação particular fecundada entre o poder público e a sua juventude local denota uma das intenções que envolvem o estudo de caso, ou seja, conforme Yin (2015, p.4), o do desejo de entender fenômenos sociais complexos permitindo que os investigadores foquem em um "caso" e retenham uma perspectiva holística e de uma problemática que envolve o mundo real. A complexidade da pesquisa realizada repousa na constatação de que existe uma necessidade da construção de um perfil de juventude por uma parcela de jovens, que acaba se relacionando com a prática de contratação de estagiários como auxiliares pedagógicos para atuarem na (s) EMEI da cidade de Santa Maria.

A partir das palavras de Pais (2016), percebemos que as expressividades e identidades juvenis, da contemporaneidade, se configuram como "performativas" uma vez que, perante as estruturas sociais cada vez mais fluídas, os jovens têm suas vidas marcadas por crescentes momentos de inconstâncias, flutuações e descontinuidades. Essas descontinuidades em suas vidas os levam a adotarem um perfil mais flexível nos seus relacionamentos, tanto pessoais, quanto profissionais. As perspectivas objetivas que outrora regiam o projeto da modernidade se flexibilizaram e a vida adulta, na atualidade, passou a assumir outras perspectivas. Entendemos que tal caráter flexível, expressamente presente na juventude santa-mariense, influi para a manutenção deste processo de contratação de jovens para serem auxiliares pedagógicos na (s) EMEI através do estatuto de estagiários.

Tentando decifrar as especificidades do caso, foram realizadas entrevistas semiestruturadas com um representante da Secretaria Municipal de Educação (SMED),

\footnotetext{
${ }^{5}$ As falas dos sujeitos entrevistados foram extraídas do TCC de autoria de Rosa Maria Bortolotti de Camargo, intitulado "As políticas públicas que envolvem o jovem estudante trabalhador do ensino médio no contexto das EMEIS de Santa Maria: primeiras discussões".
} 
uma Coordenadora Pedagógica e seis jovens estudantes da etapa do EM estagiários de uma mesma EMEI. Com respeito aos auxiliares pedagógicos, a EMEI contava com um total de 22 auxiliares, sendo seis estudantes da etapa do EM e 16 divididos entre os diversos cursos universitários de diferentes universidades da cidade. Os jovens que participaram desta pesquisa tinham entre 16 e 21 anos de idade.

No que se refere à relação entre jovens e poder local constatamos que sob o uso da palavra "parceiros" a imagem que a Coordenação Pedagógica da EMEI pesquisada e da representante da SMED possuem do jovem é contrária à imagem que o próprio jovem faz de si na realização do seu trabalho. Ou seja, ainda que o jovem entenda que sua presença é fundamental para o cuidado das crianças pequenas, ele é, no fim de tudo, um fazedor de tarefas. Para a Representante da SMED, os jovens são vistos "[...] como parceiros do processo. “[...] Em nosso município, o estagiário é parceiro e colaborador parceiro de um profissional habilitado responsável" (CAMARGO, 2015, p.40). Esta constatação pode ser complementada pela fala da Coordenadora Pedagógica da EMEI, para a mesma os jovens são "[...] funcionais, bons estagiários, mas que agem como cuidadores e fazedores de tarefas" (CAMARGO, 2015, p.40).

Compreendendo os limites das escritas dessas entrevistas, a técnica da observação participante foi fundamental para que fosse possível "[...] penetrar em um meio e tomar seus diversos aspectos [...]" (DARMON, 2004, p. 49, tradução nossa). Sendo assim, penetrar no contexto de uma EMEI contribuiu para desenhar de forma mais precisa a relação entre jovens e estágios, a qual este trabalho propunha identificar. De fato, a partir da observação participante, foi possível identificar que os jovens estagiários ocupam uma função bem institucionalizada: fazem todo o tipo de trabalho padronizado, como, levar crianças ao banheiro, ajudar na escovação dentária, cuidar as crianças na hora da pracinha e do pátio, arrumar a sala para a professora regente, organizar mochilas, trocas fraldas, entregar as crianças aos seus pais na hora da saída etc. Estes foram alguns exemplos que puderam ser observados neste processo investigativo.

Para além das observações, a partir da triangulação dos dados coletados sobre as políticas públicas educacionais nacionais e locais, as entrevistas semiestruturadas com os sujeitos já apresentados e a observação participante, foi possível construir um olhar sobre as crianças que frequentam a EI, cada vez mais numerosas, por conta da obrigatoriedade 
escolar a partir dos quatro anos, elas vivenciam a fragilidade de uma etapa de ensino ao mesmo tempo em que exercem um direito garantido.

Assim, entendemos que existe uma contradição estrutural nos processos de atender e ser atendido ou de se formar e ser formado que envolve as etapas da vida da juventude e da infância. Na sequência apresentamos algumas situações que se tornaram evidentes durante o processo investigativo, a fim de suscitar o debate sobre esta prática de estágio remunerado.

\section{Reflexões sobre as etapas do ensino médio e da educação infantil}

Antes de apresentar dados da pesquisa empírica realizada, é necessário refletir sobre algumas características que contribuem para o estudo sobre a relação entre EM e juventude, bem como EI e infância. Ressalta-se que considerando a grande quantidade de material teórico que fundamenta a história das políticas públicas da educação brasileira, julgamos pertinente não reproduzir tais conhecimentos legais, mas sim analisar as duas etapas e a relação com as duas gerações apresentadas.

A etapa do EM “[...] representa apenas os três ou quatro últimos anos da Educação Básica" (KRAWCZYK, 2011, p. 755) antes do ingresso ou não no ensino superior (ES). No que se refere às políticas de organização, os estudos que vêm sendo realizados sobre o EM revelam que essa etapa nunca teve uma identidade muito clara. Por ser considerada uma das etapas, talvez as mais controvertidas da formação do estudante, as políticas públicas educacionais para esta modalidade ainda são dificultosas e pouco solidificadas. Segundo Krazwczyk (2001) sendo o EM a última etapa da Educação Básica ele carrega um sentido dual: etapa do fim da escola obrigatória e entrada ao mundo do trabalho. Este dualismo faz com que as políticas do EM médio sejam frágeis e pouco desenvolvidas, pois os governos e especialistas não sabem como definir a etapa e, portanto, como se posicionar sobre o que se deve ou não priorizar na formação do jovem.

Como mencionado no parágrafo anterior, a contradição do EM caracteriza-se, primariamente, a partir da ideia de que ao mesmo tempo em que é etapa final dos estudos, também, é a primeira para a vida profissional do jovem. A partir desse dualismo, a história reflete que as políticas da educação média ou privilegiavam uma formação erudita dos estudos, para os jovens das camadas mais abastadas, ou privilegiavam uma formação voltada para o trabalho, notoriamente, para os jovens das camadas mais populares. 
Podemos destacar que os limites do EM denotam os limites do jovem: outrora "jovem" era uma categoria com o propósito de regular o número de ingressantes no mercado de trabalho, mas, que ainda hoje não parece ter seus objetivos, dentro da estrutura social bem clara. De fato, a juventude se constitui como a fase inicial antes da vida adulta, é o momento em que a infância é deixada para trás e os primeiros passos para as transformações biológicas, psicológicas, culturais são dados. Numa perspectiva temporal, é um dos momentos que o indivíduo irá poder ordenar suas escolhas e comportamentos, construindo um complexo de pontos de referência para a sua vida de agora e a do futuro (MELUCCI, 1997).

Ainda assim o EM parece não ser um ponto efetivamente garantido de referência para a juventude. Conforme o recente estudo sobre o EM lançado pelo Fundo das Nações Unidas para a Infância (UNICEF), no ano de 2015, os jovens no Brasil hoje, “[...] são os mais atingidos pela exclusão escolar sendo mais de 1,7 milhões deles que estão fora da escola" (VOLPI, SILVA; RIBEIRO, 2014, p. 6). O documento ainda acrescenta que:

\footnotetext{
Apesar de, nas duas últimas décadas, os indicadores tanto de acesso quanto de permanência dos adolescentes de 15 a 17 anos na escola terem melhorado, universalizar o ensino médio com qualidade permanece, ainda hoje, um dos principais desafios no campo das políticas educacionais. (VOLPI, SILVA; RIBEIRO, 2014, p. 11).
}

O relatório aponta que a escolha de realizar uma atividade remunerada, pelos jovens, concomitantemente aos estudos, é uma das principais causas do abandono escolar. A necessidade de legitimação da própria adolescência esbarra na precariedade das dificuldades financeiras, que leva uma parcela de jovens, sobretudo os das camadas mais populares, a buscarem diferentes meios e caminhos para a aquisição de recursos financeiros que os possibilitem comprarem e possuírem bens que caracterizem a sua juventude. Assim, “[...] para uma grande parcela de adolescentes, a condição juvenil só é vivenciada porque trabalham, garantindo o mínimo de recursos para o lazer, o namoro ou o consumo, além de independência” (VOLPI, SILVA; RIBEIRO, 2014, p. 64).

Os estudos sobre a cultural juvenil se elaboram, conforme apontam Salva, Tomazzetti e Ramos (2017), sobre três aspectos. O primeiro diz respeito, justamente, ao aspecto da vestimenta, da moda, ou seja, as formas como os jovens se relacionam com sociedade através das vestimentas que possuem, eles expressam suas linguagens e formas. 
O segundo e o terceiro dizem respeito a grande quantidade de trabalhos voltados para os jovens do sexo masculino e os estudos voltados para os jovens das metrópoles. Tomando como referência, os estudos sobre as formas de comunicação juvenil, através da moda:

[...] A primeira é aquela associada à música, a moda, às formas de comunicação juvenil, que aportam especificidades próprias do grupo e se referem, especialmente, às formas de vestir, às marcas realizadas nos corpos (tatuagens, piercings), artefatos e são acompanhados de componentes simbólicos (SALVA;TOMAZZETTI; RAMOS, 2017, p.100).

A partir das falas dos jovens entrevistados, verificamos que grande parte dos que ali estavam realizando o estágio remunerado na EMEI refletiam em termos de trabalho, de condições materiais de mudança de vida, e não relacionavam a sua atividade remunerada com a formação proposta pelas escolas de EM que frequentavam. Assim, Jovem 1 aponta que está realizando estágio: "Porque trabalho desde os dezesseis anos e gosto muito de trabalhar". O Jovem 2 diz: "Para poder ajudar com uma renda a mais na minha casa. O Jovem 3: "Para melhorar meus estudos." O Jovem 4 relata: "Para ajudar a minha família e comprar minhas coisas. O Jovem 5 diz que é: "Porque gasta muito". Por fim, o Jovem 6 foi o único a relacionar a escola como uma forma de experiência, o mesmo responde: "Para ter uma experiência nova saber qual profissão seguir." (CAMARGO, 2015, p.33)

Essa constatação revela que os jovens da pesquisa que optaram por esse tipo de estágio possuem uma identidade própria e aspirações particulares e confirmam, conforme Abad (2003), que a escola vem perdendo sua eficácia simbólica, não respondendo as demandas e as necessidades atuais, sobretudo, os materiais. Logo, seguindo as palavras de Charlot (2013), poder-se-ia afirmar que as controvérsias do EM não são de fato uma crise da etapa, ao contrário, se tratam de contradições dentro do seio da sociedade contemporânea socialmente desigual.

No que corresponde a história da EI, sabe-se que o cenário da constituição da sua identidade passou por acentuados momentos de definição e lutas políticas. A luta pelo direito de que a criança pequena pudesse ingressar nesta etapa se dá, resumidamente, em duas vias históricas, sendo a primeira a criação de um espaço de cuidado infantil, que serviria como instrumento dos interesses econômicos da sociedade; uma vez que a mulher pobre deveria trabalhar nas indústrias para sobreviver, e, necessitava de um lugar para deixar seus filhos durante seu tempo de trabalho. A segunda via, seria a busca pela 
compreensão da identidade da infância como uma etapa da vida e, consequentemente, da responsabilização da escola, em conjunto com a família, como promovedora da mesma.

Kuhlmann (2000) traça uma linha histórica contando que, no período da primeira revolução industrial, no Brasil, a oferta do cuidado para crianças pequenas era função das indústrias e dos setores políticos e sociais, os quais visavam a assistência de famílias pobres e trabalhadoras. O que se sucede são situações históricas e complexas em que a mesma passa a ser desde espaço de representação de ensaios de políticas educacionais para a infância, já que os pioneiros nos estudos da educação no Brasil passam a defender o espaço da EI para além do cuidar e do higienizar, até um espaço de luta feminina, uma vez que outras mulheres (não pobres) passam a desejar o direito de terem seus filhos na escola.

Atualmente, no Brasil, a partir Lei $\mathrm{n}^{\circ}$ 12.796, de 4 de abril de 2013 (BRASIL, 2013) que altera a Lei $n^{o}$ 9.394/96, de 20 de dezembro de 1996 (BRASIL, 1996) e apresenta a ampliação da obrigatoriedade escolar dos quatro aos dezessete anos de idade, a EI passa a ser etapa obrigatória na educação básica. É constituída de parâmetros e diretrizes curriculares nacionais e locais que estruturam o tipo de atendimento esperado para uma criança que frequenta a EI.

Se a garantia do acesso a esta etapa posiciona de fato o Estado como um pagador de uma dívida social com as crianças pobres e as mães trabalhadoras, bem como reafirma a luta de educadores, sobretudo, os higienistas e desenvolvimentistas, os quais se posicionaram a favor da defesa da construção de um espaço de acolhimento infantil que fosse adaptado, respeitoso e zeloso da fase da infância. Ele ofusca no debate o protagonismo infantil e a ideia de que a criança possui uma cultura própria. Tal situação de ofuscamento nos limita, de um ponto de vista sociológico, induzindo-nos a debater mais sobre uma escola que garanta condições sociais mínimas de existência para as crianças brasileiras, do que "[...] sobre a infância como construção cultural, sobre seus próprios saberes [...]" (QUINTEIRO, 2002, p. 9).

Assim, alguns questionamentos se fazem pertinentes: Afinal, o que sabemos sobre culturas infantis?" (QUINTEIRO, 2002, p. 9). Que culturas são valorizadas no seio de uma EI que contrata funcionários sem formação? Existe um diálogo ou protagonismo entre culturas juvenis e infantis? Se não se pode traçar a dimensão das possíveis respostas 
a tais questionamentos, ver-se-á que na prática do estágio remunerado a juventude, assim como a infância, tem seu protagonismo certas vezes ofuscado.

\section{Uma relação complexa com o mercado de trabalho}

Aqui, o foco é apontar e questionar, por meio de alguns resultados empíricos, em que medida a prática do estágio remunerado estabelece uma relação com a vivência da juventude.

Conforme Barros, Scramingnon, Chamarelli e Castro (2013), poucos são os estudos que apresentam a situação do auxiliar da EI. As autoras apresentam que, no período entre 1980 e 2011, apenas14 trabalhos abordaram a situação do auxiliar na EI. Assim, é difícil traçar um perfil e um debate local e nacional sobre essa função. Na pesquisa realizada, foi possível perceber, sobretudo pela observação participante, que esses profissionais não atuam como professores regentes e, em alguns casos, não possuem formação na área da educação. Os auxiliares pedagógicos do município de Santa Maria atuam como suportes para as necessidades que os professores e a escola necessitam durante a rotina diária. Do ponto de vista do jovem do EM, não existe nenhuma referência legal que os legitimem como sendo uns potenciais auxiliares pedagógicos na etapa da EI.

Em contrapartida, os "Parâmetros de Qualidade Nacionais para a Educação Infantil" (BRASIL, 2006) anunciam o tipo de profissional que deve cuidar e educar as crianças pequenas na EI. Tal documento destaca que para atuar a habilitação exigida é “[...] em nível superior, pedagogia ou modalidade normal, admitindo-se, como formação mínima, a modalidade normal, em nível Médio" (BRASIL, 2006). A modalidade normal que o documento se refere diz respeito às antigas Escolas Normais que ocorriam em nível médio e que habilitavam o estudante, tanto para o exercício da docência, quanto davam o diploma de conclusão do EM. Atualmente, esta modalidade de EM é escassa e quase inexistente e restringe ao egresso a possibilidade de atuar como docente, pois grande parte dos concursos públicos para professor da educação básica $(\mathrm{EB})$ vem exigindo cada vez mais o nível superior como prova de títulos. Na cidade de Santa Maria, não é mais aceitável no concurso para professor, por exemplo, o nível de médio normal. Para ingressar na carreira pública deve-se ter no mínimo a formação em Pedagogia nível superior. 
Esse documento também apresenta uma relação de número de professores por turma com o número de crianças a serem atendidas. Isso significa que para um limite de crianças é necessário a presença de um número $x$ de professores. Ou seja: 


\begin{abstract}
As crianças nunca ficam sozinhas, tendo sempre uma professora ou um professor de Educação Infantil para cada grupo ou turma, prevendo-se sua substituição por uma outra professora ou outro professor de Educação Infantil nos intervalos para café e almoço, para as faltas ou períodos de licença. A relação entre o número de crianças por agrupamento ou turma e o número de professoras ou professores de Educação Infantil por agrupamento varia de acordo com a faixa etária: • uma professora ou um professor para cada 6 a 8 crianças de 0 a 2 anos; $\bullet$ uma professora ou um professor para cada 15 crianças de 3 anos; • uma professora ou um professor para cada 20 crianças acima de 4 anos. (BRASIL, 2006, p. 35)
\end{abstract}

$\mathrm{Na}$ cidade de Santa Maria, estabeleceram-se as "Diretrizes Curriculares Municipais de Educação Infantil” (DCMEI), que, à luz dos Parâmetros nacionais, definiram uma relação criança/adultos e criança professor, a saber:

Tabela 2. Relação denominação/idade, criança/adultos e criança/professor

\begin{tabular}{|c|c|c|}
\hline ETAPA & IDADE & $\begin{array}{c}\text { RELAÇÃO CRIANÇA/ ADULTO } \\
\text { RELAÇÃO CRIANÇA/ } \\
\text { PROFESSOR }\end{array}$ \\
\hline Berc & -1) & $\begin{array}{l}6 \text { crianças por adulto } \\
\text { No máximo } 12 \text { crianças por professor }\end{array}$ \\
\hline $\begin{array}{ll}\text { b. } & \text { Berçário } \\
\text { (BII) }\end{array}$ & $(1-2)$ & $\begin{array}{l}\text { 6 a } 8 \text { crianças por adulto } \\
\text { No máximo } 18 \text { crianças por professor }\end{array}$ \\
\hline Maternal I (MI) & de dois a três a & $\begin{array}{l}\mathbf{1 0} \text { crianças a } 12 \text { crianças por adulto } \\
\text { No máximo } 18 \text { crianças por professor }\end{array}$ \\
\hline $\begin{array}{ll}\text { d. } & \text { Maternal } \\
\text { (MII) } & \end{array}$ & os $(3-4)$ & $\begin{array}{l}12 \text { a } 15 \text { crianças por adulto } \\
\text { No máximo } 20 \text { crianças por professor }\end{array}$ \\
\hline $\begin{array}{l}\text { e. Pré-Escola } \\
\text { A(Pré-A) }\end{array}$ & de quatro a cinco anos (4-5) & $\begin{array}{l}15 \text { a } 20 \text { crianças por adulto } \\
\text { No máximo } 20 \text { crianças por professor }\end{array}$ \\
\hline $\begin{array}{l}\text { f. Prá-Escola } \\
\text { B(Pré-B) }\end{array}$ & $\begin{array}{l}\text { de cinco anos a cinco anos e } \\
\text { onze meses }(5-5 \mathrm{a} 11 \mathrm{~m})\end{array}$ & $\begin{array}{l}20 \text { crianças por adulto } \\
\text { No máximo } 20 \text { crianças por professor }\end{array}$ \\
\hline
\end{tabular}

Fonte: Diretrizes Municipais de Educação Infantil da cidade de Santa Maria (2011,p.7).

A partir da análise desses trechos, percebe-se que a única menção que referenciaria ou justificaria o ingresso do jovem como auxiliar pedagógico nas EMEI de Santa Maria, seria a menção que fazem as DCMEI sobre a "relação criança/adulto e relação criança/professor" exposta na terceira coluna da Tabela 2. Entende-se que incrementar na terceira coluna a expressão "relação criança/adulto", uma vez que nos Parâmetros de Qualidade Nacional esta não existe, é uma forma de abrir margem para a contratação de outras pessoas para além dos diplomados em educação, sobretudo no curso de Pedagogia, para trabalharem na educação e cuidado das crianças nas EMEI. Assim, mesmo que uma sala de aula tenha um professor formado para ser responsável pela turma, os demais profissionais que o acompanharão neste trabalho podem ser "adultos" com outras formações e não professores. Assim, constatamos que, de certa forma, tal 
expressão provoca uma interpretação equivocada a qual viabiliza a contratação de profissionais que não sejam efetivamente professores ou habilitados na área da educação para atuarem como auxiliares pedagógicos, neste caso os jovens estudantes da etapa do EM.

Do ponto de vista da observação participante, percebemos que na maioria dos casos havia uma supressão de envolvimento do jovem nas ações que exercem com as crianças nos espaços da EI. Notamos que a ausência de relação entre a fase da juventude com as exigências pedagógicas do espaço de EI, não promovia a vinculação entre as intencionalidades do jovem, enquanto sujeito em formação para o mercado de trabalho, nem desenvolvia os indicadores parâmetros de qualidade exigidos na EI.

A relação que estabelece é, portanto, na sua grande parte, de necessidade financeira ${ }^{6}$. Como observamos nas falas dos jovens, anteriormente apresentadas, dos seis jovens entrevistados, quatro responderam que utilizam do seu salário para ajudar na renda da família, seja para gastar consigo mesmo ou para contribuir com seus estudos e somente um relacionou o estágio com a formação profissional.

De fato, da totalidade de jovens, a metade declarou ter uma renda familiar inferior a um salário mínimo ${ }^{7}$. Assim, constata-se, conforme Abad (2003) que o mercado do consumo é o que ordena grande parte das relações de trabalho e renda. No caso dos jovens, este mercado oferece aos mesmos, cada vez mais cedo, a promessa da liberdade a partir do poder de consumo de determinados objetos.

Isto pode ser esclarecido quando se analisa a escolha dos jovens estagiários pelos estágios nas EMEI. Como mencionado, a maioria deles não relacionou o exercício deste estágio como sendo um elo que os levaria à escolha de um trabalho para o futuro: três jovens afirmaram que a escolha pelo estágio não se relaciona com sua escolha futura (pretendem realizar curso técnico, trabalhar na enfermagem e na psicologia); dois relataram que pensam em seguir a carreira de professor e um disse que o estágio era uma oportunidade de descobrir se "queria mesmo cursar pedagogia".

\footnotetext{
${ }^{6}$ Não se pode estabelecer um valor fixo do salário dos jovens pois estes recebiam por hora trabalhada. No ano da realização da pesquisa, o valor da hora trabalhada por um estagiário em nível médio era de $\mathrm{R} \$ 5,00$. Os jovens podiam trabalhar até 6 horas diárias.

${ }^{7} \mathrm{Na}$ época o salário mínimo nacional estava calculado em $\mathrm{R} \$ 788,00$.
} 
Os relatos mostram que a escolha pelo estágio foi uma forma de obter uma renda no momento presente. Essa relação de trabalho e renda se configura como uma representação orientada pela lógica do presente já que o futuro para os jovens, sobretudo de baixa renda, “[...] fracassa em oferecer possibilidades de concretização. Neste caso, os projetos de futuros encontram-se relativamente ausentes. Ou existindo são de curso prazo" (PAIS, 2006, p.10). O autor ainda acrescenta que:

[...] os investimentos na imagem corporal contribuem para a construção da identidade dos jovens. Assim [...] a desintegração no mercado de trabalho parece dar uma compensatória integração no mercado de consumo, frequentemente com o dinheiro que vão recebendo [...] dos biscates que vão

fazendo (PAIS, 2006, p. 17).

Apesar da distância entre as práticas exercidas pelo jovem e o ideal do atendimento de crianças pequenas, nos deparamos, a partir da fala dos entrevistados que os jovens se sentem importantes para a escola e pensam que o estágio pode contribuir para suas formações pessoais, sobretudo, em termos de mercado de trabalho. O Jovem 5 , por exemplo, disse que sua participação na escola é muito importante "[...] pois todos sabem que quando algum estagiário falta faz muita falta, pois algumas turmas necessitam sempre de duas professoras". O Jovem 3 relata que "[...] é de total importância o auxílio que nós estagiários damos para o professor fazer suas atividades" (CAMARGO, 2015, p.40).

Tomando como referência os estudos de Charlot (2002) com jovens das periferias de Paris, na França, esse afirmou que entre $75 \%$ e $80 \%$ dos alunos de sua pesquisa estudam para mais tarde ter um uma atividade remunerada. Para esse autor, existia uma constatação de que de fato os jovens estudam para, futuramente, ter um bom emprego.

Transpondo sua afirmação para a realidade do estudo aqui apresentado, percebemos uma situação inversa: para os jovens desta pesquisa, os estágios remunerados são vistos como uma oportunidade de ser ter um bom currículo ou bom caminho formativo que os condicionem mais tarde para estarem bem empregados. Este aspecto foi identificado quanto os mesmos foram indagados sobre a importância do estágio em suas vidas profissionais. Obtivemos as seguintes réplicas: Jovem 1 relata que seu estágio é bom porque: "No futuro poderei ter mais conhecimentos com meus filhos e alunos". O Jovem 2 de que o estágio: "Ajuda nas coisas da vida". O Jovem 3: "De que sairá com um bom histórico para ingressar no mercado de trabalho". O Jovem 4: "De que ele terá experiências que poderão ser levadas para outras pessoas". O Jovem 5: "Porque terá um 
bom currículo". Por fim, o Jovem 6: "Porque irá ajudar a descobrir qual profissão seguir"'(CAMARGO, 2015, p.39)

Assim, entende-se que se o estágio remunerado pode de certa forma garantir um leque de possibilidades aos jovens, no sentido de que estas experiências possam facilitar a inserção dos mesmos no mercado de trabalho, além disso, existe uma relação estágio e renda utilitarista e binária: de um lado o poder local pretende garantir o funcionamento de uma política pública para a infância e de outro o jovem tenta, através do exercício remunerado, garantir seus bens materiais de existência.

\section{Considerações sobre o estudo}

Os dados apresentados neste trabalho foram elaborados com base em objetivo que consistia em identificar algumas das complexidades produzidas pelo contexto político e prático do exercício de estágios remunerados que realizam alguns estudantes do ensino médio como auxiliares pedagógicos em Escolas Municipais de Educação Infantil (EMEI). Tal objetivo levou em consideração alguns aspectos que envolvem qualidade da juventude e o atendimento de crianças pequenas.

Legalmente, tal prática está embasada pela Lei $\mathrm{n}^{\circ} 11.788$, de 25 de setembro de 2008 (BRASIL, 2008), porém, não existe registro legal que defina a qualidade dos processos de atender e ser atendido, ainda que haja determinações sobre o profissional que deve atuar na EI.

A complexidade da relação estabelecida acarretou na elaboração de alguns questionamentos: seria este estágio remunerado um diálogo inicial do jovem com o mercado de trabalho? A função de estagiário garantiria a qualidade do atendimento das crianças nas EMEI? Existe uma relação entre os estágios e a vivência da juventude?

Com efeito, em termos de mercado de trabalho, a relação estágio-renda-juventude se estabelece a partir da possibilidade de aquisição de bens de consumo e de oferta de atendimento. Os jovens estão neste processo de consumo tentando comprar uma identidade juvenil que os possibilitem legitimar uma relação simbólica com o poder.

Contudo, sabemos que a prática deste estágio remunerado é por vezes uma das poucas fontes de socialização e formação que jovens, sobretudo, da periferia terão antes de entrarem na vida adulta. Portanto, é nesse processo de dominação e subjugação, que 
fecunda um novo modelo de processo formativo, construtor de uma dignidade juvenil e que garante a liberdade financeira de alguns jovens. Conforme Charlot (2013):

[...] interessa-nos aqui pelo significado que confere ao trabalho. Permanece este uma obrigação, um marco de dominação e sujeição: é o escravo que trabalha. Mas passa também a ser um processo de libertação: quem trabalha se forma e, por isso, ganha poder, dignidade, liberdade. O trabalho é ao mesmo tempo dependência, luta e conquista (CHARLOT, 2013, p. 69).

No que se refere à qualidade de atendimento na EI, se esse atendimento for prestado pelo jovem não representa os parâmetros de qualidade e ofusca o protagonismo infantil, no sentido que parece não se respeitar o direito das crianças em ter um profissional habilitado para o seu atendimento, reconhecemos que a implementação da obrigatoriedade escolar, dos quatro aos dezessete anos, garante que a criança pequena acesse à EI, cada vez mais cedo. Este acesso possibilita que a mesma tenha a oportunidade de evoluir no contexto escolar de uma forma muito mais satisfatória do que se não tivesse tido acesso à EI. Sabe-se que:

\begin{abstract}
A criança que frequenta a EI acaba tendo, em média, um ano a mais de escolaridade do que a que entra na escola a partir do Ensino Fundamental e $32 \%$ mais possibilidades de concluir o EM, benefício que é mais acentuado entre as crianças de famílias mais carentes [...]. Isso acontece porque esses estudantes acabam desenvolvendo mais motivações para permanecer na escola, mesmo com dificuldades de aprendizado, e porque, ao ter mais tempo de exposição aos conteúdos dos anos iniciais de escolarização, chegam com melhor nível de conhecimento às etapas seguintes
\end{abstract}

(FUNDO DAS NAÇÕES UNIDAS PARA A INFÂNCIA, 2012, p. 88).

Se o ato de um estágio que não esteja associação ao seu sentido pessoal e vida do jovem rompe em partes com o sentindo de uma vivência de juventude plena, pois limita os jovens a realizarem um ato remunerado somente para manterem suas necessidades materiais. Em contrapartida, não se pode negar que a prática dos estágios é conveniente, tanto para os jovens que precisam de dinheiro, quanto para as escolas que precisam auxiliares que sejam "parceiros" de professores regentes nas salas de EI já que existe uma falta de estudantes dos cursos do ES, da área da educação, que poderiam estar atuando nesta função ${ }^{8}$.

Concluímos com a afirmação de que, ainda que existam complexidades legais e práticas nos processos de atender e ser atendido e de formar e ser formado, no contexto

\footnotetext{
${ }^{8}$ Aqui vale ressaltar que a cidade de Santa Maria possui uma universidade federal, além das privadas, que oferta o Curso de Pedagogia na modalidade diurno e noturno. Não obstante, como visto, poucos são os acadêmicos que realizam estágios na (s) EMEI.
} 
dos estágios remunerados praticados por jovens do EM nas EMEI, estas são o que vem possibilitando, com os esforços, tanto SMED e da Coordenação da escola, quanto dos jovens, o atendimento de um maior número de crianças na etapa da EI, a partir da garantia de mais uma pessoa trabalhando com o professor regente, mesmo que seja de forma funcional.

Igualmente, são essas mesmas relações complexas que vem fornecendo subsídios financeiros aos jovens com baixa renda e contribuindo com a sua construção identitária e sustento familiar. Por fim, reconhecemos que as problematizações aqui sustentadas deixam o campo da pesquisa sobre esta temática aberto aos questionamentos, um deles é sobre o feito de não considerarmos o perfil dos auxiliares pedagógicos da (s) escolas de EI privadas: Seriam eles, os estudantes dos cursos de Pedagogia ou da área da educação ou ainda jovens do EM? Logo, compreende-se que tais complexidades, seguramente, não se esgotam nas proposições deste estudo.

\section{REFERÊNCIAS BIBLIOGRÁFICAS}

ABAD, M. Crítica política das políticas de juventude. In: FREITAS, M.V., PAPA, F.C. (Org.) Políticas públicas: juventude em pauta. São Paulo: Cortez, 2003.

BARROS, C., SCRAMINGNON, G., CHAMARELLI, L. CASTRO, M. Algumas faces da formação: entre políticas municipais e o cotidiano da educação infantil. In: KRAMER, S., NUNES, M.F., CARVALHO, M. C.(Org.). Educação Infantil: formação e responsabilidade. Campinas: Papirus, 2013.

BRASIL. Lei $\mathbf{n}^{\mathbf{0}}$ 1. 788, de 25 de setembro de 2008. Dispõe sobre o estágio de estudantes; altera a redação do art. 428 da Consolidação das Leis do Trabalho - CLT, aprovada pelo Decreto-Lei no 5.452, de 1o de maio de 1943, e a Lei no 9.394, de 20 de dezembro de 1996; revoga as Leis nos 6.494, de 7 de dezembro de 1977, e 8.859, de 23 de março de 1994, o parágrafo único do art. 82 da Lei no 9.394, de 20 de dezembro de 1996, e o art. 6o da Medida Provisória no 2.164-41, de 24 de agosto de 2001; e dá outras providências. Congresso Nacional. Brasília, DF. Disponível em: <http://www.planalto.gov.br/ccivil_03/_ato2007-2010/2008/lei/111788.htm>. Acesso em: 6 jun. 2015.

Lei no 8.069, de 13 de julho de 1990. Dispõe sobre o Estatuto da Criança e do Adolescente e dá outras providências. Congresso nacional. Brasília, DF. Disponível em: <http://www.planalto.gov.br/ccivil_03/Leis/18069.htm>. Acesso em: 7 jan. 2015 
Lei $n^{\circ}$ 9.394/96, de 20 de dezembro de 1996. Estabelece as diretrizes e bases da educação nacional. Congresso nacional. Brasília, DF. Disponível em : $\langle$ http://portal.mec.gov.br/arquivos/pdf/ldb.pdf >. Acesso em: 29 jun. 2015.

Parâmetros Nacionais de Qualidade para a Educação Infantil. Disponível em : <http://portal.mec.gov.br/arquivos/pdf/ldb.pdf>. Acesso em: 29 jun. 2015.

Lei $\mathbf{n}^{\circ}$. 12.527, de 18 de novembro de 2011. Regula o acesso a informações previsto no inciso XXXIII do art. 5o, no inciso II do $\S 3$ odo art. 37 e no $§ 20$ do art. 216 da Constituição Federal; altera a Lei no 8.112, de 11 de dezembro de 1990; revoga a Lei no 11.111, de 5 de maio de 2005, e dispositivos da Lei no 8.159, de 8 de janeiro de 1991; e dá outras providências. Congresso Nacional. Brasília, DF. Disponível em: <http://www.planalto.gov.br/ccivil_03/_ato2011-2014/2011/lei/112527.htm>. Acesso em: 29 jun. 2015.

Lei no 12. 796, de 4 de abril de 2013. Altera a Lei no 9.394, de 20 de dezembro de 1996, que estabelece as diretrizes e bases da educação nacional, para dispor sobre a formação dos profissionais da educação e dar outras providências. Congresso Nacional. Brasília, DF. Disponível em: <http://www.planalto.gov.br/ccivil_03/_ato2011-2014/2013/lei/112796.htm>. Acesso em: 10 mai. 2015

Ministério da Educação. Instituto Nacional de Pesquisas Educacionais Anísio Teixeira. Disponível em: 〈http://portal.inep.gov.br〉. Acesso em: 7 jun. 2015.

CAMARGO, B.R.M. As políticas públicas que envolvem o jovem estudante trabalhador do ensino médio no contexto das EMEIS de Santa Maria: primeiras discussões. 2015. 64f. Trabalho de Conclusão de Curso. Universidade Federal de Santa Maria, Centro de Educação, Curso de Pedagogia - Santa Maria: 2015.

CHARLOT, B. Relação com a escola e o saber nos bairros populares. Perspectiva. Florianópolis, v.20, n. especial, p. 17-34, jul. / dez. 2002.

Da relação com o saber às práticas educativas. São Paulo: Cortez,2013.

DARMON, M. La socialisation. Domaine et Aproches. 2. ed. Paris: Armand Colin, 2004.

FUNDO DAS NAÇÕES UNIDAS PARA A INFÂNCIA. Iniciativa global para as crianças fora da escola-Brasil. Brasília: UNICEF, 2012.

KRAWCZYK, N. Reflexão sobre alguns desafios do ensino médio no Brasil hoje. Scielo. São Paulo, v. 41, n. 144, s/p, 2011.

KUHLMANN, M. Jr. História da educação infantil brasileira. Revista Brasileira de Educação. s/v, n. 14, p. 5 - 17, 2000. 
MELUCCI, A. Juventude, tempo e movimentos sociais. Revista Brasileira de Educação. Estocolmo, v.4, n.2, p.3-14, mai. / jun. / jul. /ago. 1997.

PAIS, J.M. Buscas de si: expressividades e identidades juvenis. In: ALMEIRA, M.I.M., Eugenio, F. (Org.) Culturas jovens: novos mapas do afeto. Rio de janeiro: Jorge Zahar, 2006.

QUINTEIRO, J. Infância e Educação no Brasil. In: FARIA, A.L.G., Dermartini, Z.B.F., Prado, P.D. (Org.) Por uma cultura da infância: metodologias de pesquisa com crianças. 3. ed. Campinas, SP: Autores Associados, 2009.

SANTA MARIA. Secretaria do Município da Educação. Diretrizes Curriculares Municipais para a Educação Infantil. Santa Maria, 2011 Disponível em:

$<$ http://profefgpelf.files.wordpress.com/2012/08/diretrizes-curiculares-1.pdf>. Acesso em: 02 fev. 2015.

SALVA, S.; RAMOS, N.V.; TOMAZZETTI, E.M.; RAMOS, E.S.S. Nas margens do ensino médio. Jovens de escolas públicas em processo de afastamento. Santa Maria, RS: Editora e Gráfica Curso Caxias, 2017.

VOLPI, M., SILVA, M.S., RIBEIRO, J. (Org.). 10 desafios do ensino médio no Brasil: para garantir o direito de aprender de adolescentes de 15 a 17 anos. Brasília, DF: UNICEF.

YIN, R.K. Estudo de caso: planejamento e método. 5. ed. Porto Alegre, Bookman, 2015.

Recebido em: 08/04/2017

Aprovado em: 04/10/2017 